From the above measurements, a preliminary value of $B_{0}^{\prime}=1.53 \mathrm{~cm} .^{-1}$ is obtained. The values of $B^{\prime \prime}$ are already known from the work of Scheib (loc. cit.), since the $\alpha$ and $\beta$ bands have the same final state.

Physical Laboratory, A. Elliotis.

University of Utrecht.

\section{Sputtered Nickel Films and the Synthesis of Ammonia.}

I HAVE recently found that when a film which has been sputtered from a nickel cathode in an atmosphere of nitrogen is afterwards heated to $150^{\circ} \mathrm{C}$. or more in hydrogen, ammonia is produced. The process undoubtedly consists in the reduction of a nitride of nickel formed in sputtering : the quantity of ammonia -10-20 mgm. for a film of perhaps $200 \mathrm{sq}$. cm. - checks reasonably well with the amount of nitrogen absorbed in sputtering. Heating in a large excess of hydrogen, with added nitrogen, has not as yet been found to increase appreciably the yield of ammonia, so the process does not appear to be catalytic in the ordinary sense-for the pressures and temperatures tried so far.

Of course, the production of ammonia from nitrides is common (cf. the Serpek process), and the nitride of nickel is not unknown (see, for example, Beilby and Henderson, Jour. Chem. Soc., 79, 1251; 1901: Vournasos, C.R., 168, 889; 1919). The chief novelty in the present work, aside from the method of production of the nitride, is the comparatively low temperature at which the reaction takes place. This is probably due to the nitride being produced in sputtering in a very finely divided form (although doubtless still crystalline, cf. Ingersoll and Hanawalt, Phys. Rev., 34, 975; 1929).

It may be pointed out that the sputtering processwhen used under conditions such as the present, of relatively high gas pressure and low voltage-offers a method, hitherto little used, for the formation of many unusual compounds or quasi-compounds. With the metal (probably) in the vapour state and the gas largely excited, combinations are certainly to be expected (cf. v. Hippel, Ann. d. Phys., 81, 1072; 1926), if they are at all possible. Conditions of current density and gas pressure are likely to be somewhat critical. In the present case nitrogen is most rapidly absorbed in sputtering when the pressure is about $0.5 \mathrm{~mm}$., with a current density around half a milliampere per sq. cm. of film surface, at 1500 volts. Too high a current, or insufficient cooling, breaks down the compound as fast as formed. Heating to $300^{\circ} \mathrm{C}$. decomposes this nitride, driving off the gas and leaving a crystalline film of metallic nickel. If pure compounds are to be formed in this way, the cathode should be in a thin strip form which can be given a preliminary heating to redness for some time, as otherwise the gas released from the metal in sputtering forms a serious source of contamination.

Department of Physics,

University of Wisconsin, July 9.

\section{Spitsbergen Whale Fishery of the Seventeenth} Century.

As is well known, in the seventeenth century a right-whale fishery was prosecuted in the inlets of West Spitsbergen, the whales being caught by boats launched from the shore. Were the whales caught at this fishery Greenland whales, as is asserted, or were they, as seems more likely, Atlantic whales?

No. 3171, VoL. 126$\rceil$
In 1827, on May 14, Parry ${ }^{1}$ found Mauritius Bay, on the shore of which Smeerenberg, the Dutch whaling station, stood, still frozen over, the edge of the land ice or land-floe extending across its mouth from Hakluyt's Headland to Vogel Sang; in 1880, on July 20, the late Mr. Leigh Smith ${ }^{2}$ found Fair Haven blocked with ice; and last year in June, according to a Danish Meteorological Office report, ${ }^{3}$ Foreland Sound was still frozen over.

Taking the foregoing and certain other facts connected with the ice into consideration, the inshore fishery of the seventeenth century must have been prosecuted in July and August, months in which the inlets of West Spitsbergen are usually free from 'land ice", that is, the ice that forms in situ in the winter months. Until this kind of ice breaks and drifts away, the fishery could not be prosecuted by boats launched from the shore.

The Greenland whale is a migratory animal, keeping amongst or in the near vicinity of the polar ice and in water having a temperature never much above its freezing-point. According to the log books of Scoresby, senior, it was only seen near Spitsbergen in April. In May and June it had to be looked for amongst or near the ice half-way between Spitsbergen and Greenland, and even this situation it usually deserted in the latter month. In July and August it had usually to be looked for in a lower latitude near the Greenland coast, but in that situation it was seldom seen except in limited numbers and only when there was plenty of ice.

The Atlantic whale is also a migratory animal, migrating north in summer and south in winter, but it prefers ice-free waters with a temperature well above their freozing-point. In recent years it has been seen so far north as Iceland and Bear Island; and west of Spitsbergen, where the temperature of the water is unusually high, it may quite well have gone still farther north.

Exmouth, July 14.

1 Parry. "Narrative of an Attempt to Reach the North Pole." - Voyage of the Eira; Proc. Roy. Geo. Soc., p. 140, 1881.

s "The State of the Ice in the Arctic Seas, 1929."

\section{Distribution of the Pigmy Hippopotamus.}

UNTIL Major Hans Schomburgk's search in 1911-12 for the headquarters of the pigmy hippopotamus (Choeropsis liberiensis), little was known of its distribution except that it hailed from the country to which it owes its specific name. Schomburgk found that it extended from the coastal belt of Liberia back to the boundary of French Sudan, but how far it spread along the coast into Sierra Leone and French Ivory Coast he could not discover ("Distribution and Habits of the Pigmy Hippopotamus ", in 17th Ann. Rep. New York Zoo. Soc., 1912 (pub. 1913), pp. 113-120). His farthest east record is from Du Queah (Dukwia) River, on the boundary between the Mamba and the Bassa Country, about $10^{\circ} 15^{\prime} \mathrm{W}$. long.

Two skulls, recently presented to the Royal Scottish Museum by Mr. J. B. I. Mackay, were given to him in 1928 by the chief of Abo. The animals to which these skulls belonged lived in marshy ground of limited area not far from the banks of the Niger and within a hundred miles of its mouth, more than a thousand miles west of previous records. I do not specify the locality more definitely, because, although the animals are sufficiently numerous to warrant the attentions of a professional native hunter who spends most of his time in the dry season hunting them, they might readily be exterminated owing to the circum. scribed area inhabited, and in spite of the moderate protection granted by law. 